\title{
Kisses of Death in the Graduate School Application Process
}

\author{
Drew C. Appleby \\ Indiana University-Purdue University Indianapolis
}

\author{
Karen M. Appleby \\ Idaho State University
}

A survey of psychology graduate admissions committee chairs revealed 5 categories of mistakes applicants make that diminish their probability of acceptance. We discuss 3 strategies that psychology departments can use to decrease the likelihood that students will commit these mistakes in their graduate school applications and provide suggestions that will help students avoid these mistakes.

The ideal student, seen through the eyes of graduate faculty, is gifted and creative, very bright and extremely motivated to learn, perfectly suited to the program, eager to actively pursue the lines of inquiry valued by the faculty, pleasant, responsible, and devoid of serious personal problems.

$$
\text { —Keith-Spiegel \& Wiederman (2000, p. 32) }
$$

This statement indicates that applicants must convey these impressions to graduate school admissions committees throughout the application process to gain acceptance into graduate programs. Numerous authors have offered advice to undergraduate psychology majors about gaining admission to graduate programs during the past decade (Appleby, 2003a; Buskist \& Sherburne, 1996; Keith-Spiegel \& Wiederman, 2000; Kinder \& Walfish, 2001; Kuther, 2003, 2004; Landrum \& Davis, 2003; Lloyd, 2001; Morgan \& Korschgen, 2005; Peterson's, 2001; Sayette, Mayne, \& Norcross, 2004; Taylor-Cooke \& Appleby, 2002). Despite this wealth of valuable information, few authors advise students about what they should not do when applying to graduate school. When authors do offer this advice, few support it with data.

We surveyed chairs of graduate school admissions committees in psychology about the characteristics of graduate school candidates that decrease their chances for acceptance (i.e., kisses of death [KODs]). Our data provide faculty who mentor, advise, and teach psychology majors with strategies to enable their students to avoid KODs when they apply to graduate school.

\section{Method}

We mailed a letter addressed to the Chair of the Graduate Admissions Committee to each of the 457 psychology graduate programs listed in the American Psychological Association's (2001) Graduate Study in Psychology 2001. The letter explained the purpose of the study and asked participants to provide "one or two examples of kisses of death you have encountered during your career." We defined KODs in the letter as "aberrant types of information that cause graduate admissions committees to reject otherwise strong applicants."

\section{Data Analysis}

Eighty-eight of the 457 chairs (19\%) returned their surveys, and these responses yielded 156 examples of KODs. This relatively low response rate is common in qualitative research that uses open-ended questions because, although this type of question gives respondents freedom to "expand on ideas," it often "requires more time to answer than closed questions" (Thomas \& Nelson, 2001, p. 263). We qualitatively analyzed the 156 examples of KODs according to the following procedures (Miles \& Huberman, 1994; Patton, 1990). First, we independently inductively analyzed each example (McCracken, 1988). This approach required us to consider each response individually and to identify its central theme (poorly written application, harmful letter of recommendation, or lack of interest in research). Second, we independently grouped these inductive findings into categories, or "words, phrases, sentences, or whole paragraphs, connected ... to a specific setting" (Miles \& Huberman, 1994, p. 56), that described broad situations in which several similar KODs occurred (e.g., we placed an example identified as an inappropriate letter of recommendation author under the major heading for harmful letters of recommendation). Third, we conducted "analyst triangulation" (Patton, 1990, p. 468) by comparing our findings from Step 1 and our categories from Step 2. This procedure yielded a set of themes that were both internally consistent (i.e., all categories contained numerous similar responses) and externally representative of broad examples of KODs (Patton, 1990).

\section{Results}

We identified the following five major KOD categories: (a) damaging personal statements, (b) harmful letters of recommendation, (c) lack of program information, (d) poor writing skills, and (e) misfired attempts to impress. We subsequently describe these categories in descending order of frequency accompanied by illuminating examples.

\section{Damaging Personal Statements}

The personal statement section of a graduate school application is an opportunity to inform an admissions committee about personal and professional development, academic background and objectives, research and field experiences, and career goals and plans (Keith-Spiegel \& Wiederman, 2000). We found 53 responses related to damaging personal 
statements, which we sorted into four subcategories: personal mental health, excessive altruism, excessive self-disclosure, and professional inappropriateness.

Personal mental health. The discussion of a personal mental health problem is likely to decrease an applicant's chances of acceptance into a program. Examples of this particular KOD in a personal statement included comments such as "showing evidence of untreated mental illness," "emotional instability," and seeking graduate training "to better understand one's own problems or problems in one's family." More specifically, one respondent stated that a KOD may occur "when students highlight how they were drawn to graduate study because of significant personal problems or trauma. Graduate school is an academic/career path, not a personal treatment or intervention for problems."

Excessive altruism. Several respondents described personal statements that expressed excessively altruistic professional goals as KODs. Admissions committees are not impressed by statements such as "I want to help all people," "I'm destined to save the world," or "I think I am a strong candidate for your program because people have always come to me with their problems; I am viewed as a warm, empathetic, and caring person." One respondent offered the following advice: "Everybody wants to help people. That's assumed. Don't say the reason you want to go into clinical psychology is to help people." Thus, a personal statement should focus on the student's professional activities such as research interests and pursuits, academic strengths, and professional experiences rather than on purely personal characteristics and motives. It is better to allow letter of recommendation authors to describe strong personal qualities than to include them as self-perceptions in a personal statement.

Excessive self-disclosure. Promiscuous self-disclosure characterized another KOD in personal statements. An example of such disclosure was "a long saga about how the student had finished [school] over incredible odds. Much better to have a reference allude to this." However, one committee chair noted that graduate admissions committees do not always view this type of information negatively if an applicant has written it in a professional manner that is appropriate for the context of a formal application.

The applicant mentions in the personal statement that he/ she decided to pursue a career in clinical psychology due to personal family experience with psychopathology. This isn't always a kiss of death, but a sensitive area such as this should be communicated carefully. If the applicant is "spilling" overly personal information in a written statement, I often view this as a "worry sign" or an indication of poor interpersonal boundaries.

Professionally inappropriate. A final example of a KOD that can occur in a personal statement is any professionally inappropriate information that does not match the context of the application. One applicant admitted to feeling "a thrill of excitement every time he/she steps into a morgue." Another wrote "a 10-page narrative of herself as Dorothy on the yellow-brick road to graduate school." A third indicated that he or she "had performed (acted?) in pornographic movies, which was not well received by the admissions department in consideration for acceptance into graduate school." Other types of professionally unsuitable content include using excessive or inappropriate humor, "cutesy/clever stuff," and excessively religious references (e.g., "I am a gifted therapist naturally. God has given me natural talents that make me a very good clinician. This was recently demonstrated when I helped my devil-worshipping brother go on the right path, God's path."). As one respondent noted, "Being religious is $\mathrm{OK}$, but it has little relevance to research or psychology graduate school."

\section{Harmful Letters of Recommendation}

A total of $45 \mathrm{KOD}$ examples centered on letters of recommendation. The two most harmful aspects of these documents centered on undesirable applicant characteristics and letters from inappropriate sources.

Undesirable applicant characteristics. To excel in graduate school, a student must possess fundamentally positive personal characteristics such as intelligence, motivation, responsibility, and agreeableness (Keith-Spiegel \& Wiederman, 2000). Therefore, any letter of recommendation suggesting that a student does not possess these qualities can be a KOD. Statements such as "arrogant, not a team player, and self-centered"; "unreliable, manipulative, and immature"; "strong will and imposing character"; "does not like research"; and "scattered and needs some direction" are detrimental to a student's acceptance chances. One respondent noted that a KOD can occur if the letter included "a lack of superlatives. The student has to rise above competency." Finally, a personality characteristic deemed vital for a graduate student was the ability to work independently. For example, a KOD may occur if

The letter of recommendation somehow suggested that the applicant has trouble working independently and is not clearly intrinsically motivated. Then that person would be at a serious disadvantage. Admissions committees believe that graduate school is a challenging and demanding experience. Successful applicants must have the motivation to succeed and the perseverance to carry through even when obstacles are encountered.

Inappropriate sources. Applicants should choose their letter of recommendation authors carefully. "Letters of recommendation should be from professors or other individuals who have been involved in the student's education and research activities ... they should NOT be from relatives or employees." Participants suggested that "letters of recommendation from odd sources such as ministers or family friends and letters of recommendation from faculty members who did not know the applicant well" are KODs. Other inappropriateand therefore damaging-authors included "therapists," "travel agents," "parents," "boyfriend[s] or girlfriend[s]," "family friends," and "the applicant." Letters of recommendation should come from people who can truthfully describe the applicant's work habits and potential as a graduate student (Buskist \& Sherburne, 1996). 


\section{Lack of Information About the Program}

A total of $22 \mathrm{KOD}$ examples identified applicants' lack of knowledge about the program to which they were applying. These examples included not researching the general focus of the program and not exploring how the applicant's research interests fit the focus of the program.

Program focus. Advisors cannot overemphasize the importance of researching the focus of the programs to which their students apply. For example, KODs occur when applicants "demonstrate no clue regarding what the foci of the program are" or "haven't bothered to see what kind of work is done in our program." Studying the current research interests of graduate faculty at schools to which they apply is also crucial. One respondent advised, "applicants should do some background reading on the faculty, read their publications, and be able to say how their research interests and career goals fit with Dr. X." Another respondent supported this point with the following statement:

Students who express an interest in research activity that does not correspond to the research interests of our faculty are not likely to be admitted. This is especially true if the student appears set on doing research in his or her area of interest.

This idea was further supported by another respondent, who stated that a KOD occurs when "students note that they wish to work with a specific faculty member who has retired, died, or relocated."

Fit into the program. A crucial aspect of researching a graduate program involves applicants' comparison of their research interests with the research activities of a program's faculty. The importance of applicant-program fit is crucial for both the professor and the student to receive maximum professional gains from the relationship (Buskist \& Sherburne, 1996). One participant noted

\begin{abstract}
I'm very attentive to whether a student's interest matches our training. I expect a statement of personal interest that displays a convincing, compelling desire for what we have to offer from its start to finish. It's a kiss of death when I read a personal essay that describes an applicant's life-long goal of serving humankind and has a paragraph tacked on to the end that "personalizes" the essay for the particular school to which it was sent.
\end{abstract}

Another participant noted that students must "do homework on each program. Statements from applicants that state the program is just perfect for them, without evidence they know much about the program other than its specialty name" are KODs.

\section{Poor Writing Skills}

Completing an application for graduate school is much like writing a manuscript. The application must include appropriate content, but it must also be cohesive, organized, concise, written skillfully, and proofread thoroughly (Buskist \& Sherburne, 1996). A total of $21 \mathrm{KOD}$ examples pertained to poorly written applications, which we divided into two major subcategories: spelling and grammatical errors and poorly written applications.

Spelling and grammatical errors. According to several respondents, spelling and grammatical errors found anywhere in the application are an immediate KOD. Comments such as "writing that abuses the rules of grammar," "misspellings," and "letters that display grammar and punctuation errors" all point to the importance of proofreading materials included in an application packet. Another respondent elaborated on this point by saying, "It is not so much the student's lack of writing ability, but rather the carelessness of sending such sloppy work to an admissions committee that bodes ill."

Poorly written application materials. Poorly written material or material weak in content is another KOD. Students should write their personal statements concisely, but in enough detail to reflect their research, educational, and professional goals clearly. One respondent stated that a KOD occurs when he or she reads "overly long and detailed statements of purpose that are poorly edited." Overall structure is also important because a statement of purpose is a chance to demonstrate strong writing skills, a crucial characteristic of successful graduate students. One respondent succinctly stated that a KOD exists in applications that "lack structure. People who want to get their doctorate should already know how to write."

\section{Misfired Attempts to Impress}

The final KOD category included six examples of students' misfired attempts to impress admissions committees. Applicants should assiduously avoid the following failed efforts to make a positive impression on admissions committees.

Admissions committees do not respond favorably to applicants who attempt to impress them by being critical of their undergraduate programs or offering unsupported praise for the graduate program to which they are applying. For example, one applicant said "My undergraduate program was really bad because of $x, y$, and $z$. I didn't really learn anything, so I'm applying to your program so that I will actually learn something." One participant mentioned, "the candidate will give a very bad impression if he/she blames others for his/her poor academic record. Example: Faculty here at X university were unwilling to help me succeed in this course." Another respondent cited a similar KOD when he or she suggested that, "statements in the personal statement that are openly and overly critical of one's undergraduate institution or quality of preparation are [a kiss of death]."

Attempting to impress admissions committees by name dropping influential practitioners of psychology or other wellknown public officials may be an unsuccessful strategy to gain admission to graduate school. For example, statements of purpose that "elaborate on [the applicant's] family's work history in the area of psychology or mental health and/or namedrop some recognized practitioner without any substantive evidence of having a real connection" are often a KOD. Another example included obtaining letters of recommendation from political sources who may be influential within gov- 
ernment agencies, but who are inappropriate candidates to recommend the applicant for graduate study in psychology. For example, one KOD occurred when

an applicant included a letter of recommendation from a state senator who was a friend of the family and only knew the applicant as a child and adolescent. The letter said little about the applicant and described the senator's powerful role in overseeing the funding of higher education in the state.

\section{Discussion and Recommendations}

Although the KODs identified in this study reflect unwise choices on the part of applicants, we believe many of these KODs resulted more from a lack of appropriate advising and mentoring than from a lack of applicants' intelligence. Unless undergraduate psychology programs provide appropriate advising and mentoring opportunities, their majors are likely to commit many of these KODs because of a lack of exposure to information that would otherwise enable them to understand the graduate school culture, the requirements of the graduate school application process, and the exact nature of some of its components. For example, an unmentored psychology major may interpret a personal statement at face value by perceiving it as an opportunity to share personal (i.e., private) information with the members of a graduate admissions committee. Unless applicants know that a personal statement should address issues such as research interests and perceived fit with a program, they may misinterpret its purpose and write personal statements that inadvertently doom their applications. Similarly, an unmentored student may interpret a letter of recommendation as a request for information from a person who knows her or him well and can vouch for her or his admirable traits and strong values (e.g., a family member or a member of the clergy).

We believe undergraduate psychology programs can prepare their students to construct successful graduate school applications that do not contain KODs in the following three ways: (a) mentoring, (b) academic advising, and (c) teaching classes designed to prepare students for their lives after undergraduate school. Keith-Spiegel and Wiederman (2000) defined a mentor as "an established professional in the student's general study area who facilitates the student's undergraduate accomplishments and the path to graduate school" (p. 67). Although some departments may have official mentoring programs, most mentor-protégé relationships are likely to develop when students participate in research conducted by faculty. Departments can help their students understand the importance of research participation in the graduate school selection process by sponsoring informal social gatherings for undergraduates to talk with graduate students (Appleby, 2000b). Likewise, departments can promote mentoring by engaging in community-building strategies that encourage closer relationships among students and faculty (Appleby, 2000a). Effective mentoring of undergraduate students can help them attain the research and classroom experiences that facilitate strong letters of recommendation, compelling personal statements, and proficient writing skills. These experiences can help students avoid KODs in their graduate applications.
Academic advising is a second strategy that departments can use to help their undergraduates avoid KODs. Ware et al. (1993) described the role of advisers in preparing their advisees for their postbaccalaureate educational aspirations:

Advisers may encourage students to seek a match between personal characteristics (e.g., values, interests, skills, etc.) and characteristics of the graduate program. Additional advising tasks include establishing a realistic time line, preparing applications (including a goals statement), taking the Graduate Record Examination (or other standardized test), and selecting faculty to write letters of recommendation. (p. 58)

This process, known as developmental advising (Crookston, 1972), reflects the conscious effort of advisors to help advisees understand how their undergraduate program can help them develop into the people they wish to become (Appleby, 2002). Unfortunately, this type of timeconsuming, one-on-one advising may not be available to all psychology majors because many departments lack the human resources to provide it.

The third strategy to help students avoid KODs is to provide them with a class that familiarizes them with the nature of graduate education and the graduate application process. Oles and Cooper (1988) described a class titled Professional Seminar that allowed "one faculty member, together with volunteer help, to provide 150 students with 13-14 hours of academic advising each semester for a total of 1400 contact hours" (p. 63). Although the primary focus of this class was to familiarize students with their program's faculty, curriculum, and research opportunities, it also included information about graduate school and required its enrollees to write a paper that included "their plans for graduate school" (p. 62). Classes of this nature have increased in the 17 years since Oles and Cooper described their pioneering seminar. Now $34.2 \%$ of psychology departments that answered a survey about this type of class reported offering one (Landrum, Shoemaker, \& Davis, 2003).

The purpose of these classes is to provide students with academic and career advising information that may otherwise be unavailable, overlooked, or ignored. When taught well and taken seriously, these classes provide students with the guidance and encouragement they need to identify their career goals and understand how they can use their undergraduate curricular and extracurricular opportunities to accomplish these goals (Appleby, 2003b). When Landrum et al. (2003) asked departments that offered such a class how important it was for enrollees to gain knowledge about 33 issues typically taught in these classes, the ratings (on a 0 to 3 scale, with 3 being extremely important) were 2.50 for "know the information needed to apply to graduate programs," 2.30 for "know how to apply to graduate school," and 2.11 for "know the value of letters of recommendation" (p. 49). Students who possess this type of knowledge are much less likely to commit KODs than their peers who are unaware of this information.

Not all psychology departments possess the resources to offer their students a full range of mentoring, advising, and academic opportunities designed to prevent them from committing KODs in the graduate school application process. However, we believe that most departments can provide at 
Personal statements

- Avoid references to your mental health. Such statements could create the impression you may be unable to function as a successful graduate student.

- Avoid making excessively altruistic statements. Graduate faculty could interpret these statements to mean you believe a strong need to help others is more important to your success in graduate school than a desire to perform research and engage in other academic and professional activities.

- Avoid providing excessively self-revealing information. Faculty may interpret such information as a sign you are unaware of the value of interpersonal or professional boundaries in sensitive areas.

- Avoid inappropriate humor, attempts to appear cute or clever, and references to God or religious issues when these issues are unrelated to the program to which you are applying. Admissions committee members may interpret this type of information to mean you lack awareness of the formal nature of the application process or the culture of graduate school.

Letters of recommendation

- Avoid letters of recommendation from people who do not know you well, whose portrayals of your characteristics may not objective (e.g., a relative), or who are unable to base their descriptions in an academic context (e.g., your minister). Letters from these authors can give the impression you are unable or unwilling to solicit letters from individuals whose depictions are accurate, objective, or professionally relevant.

- Avoid letter of recommendation authors who will provide unflattering descriptions of your personal or academic characteristics. These descriptions provide a clear warning that you are not suited for graduate study. Choose your letter of recommendation authors carefully. Do not simply ask potential authors if they are willing to write you a letter of recommendation; ask them if they are able to write you a strong letter of recommendation. This question will allow them to decline your request diplomatically if they believe their letter may be more harmful than helpful.

Lack of information about the program

- Avoid statements that reflect a generic approach to the application process or an unfamiliarity with the program to which you are applying. These statements signal you have not made an honest effort to learn about the program from which you are saying you want to earn your graduate degree.

- Avoid statements that indicate you and the target program are a perfect fit if these statements are not corroborated with specific evidence that supports your assertion (e.g., your research interests are similar to those of the program's faculty). Graduate faculty can interpret a lack of this evidence as a sign that you and the program to which you are applying are not a good match.

Poor writing skills

- Avoid any type of spelling or grammatical errors in your application. These errors are an unmistakable warning of substandard writing skills, a refusal to proofread your work, or willingness to submit careless written work.

- Avoid writing in an unclear, disorganized, or unconvincing manner that does not provide your readers with a coherent picture of your research, educational, and professional goals. A crucial part of your graduate training will be writing; do not communicate your inability to write to those you hope will be evaluating your writing in the future.

Misfired attempts to impress

- Avoid attempts to impress the members of a graduate admissions committee with information they may interpret as insincere flattery (e.g., referring to the target program in an excessively complimentary manner) or inappropriate (e.g., name dropping or blaming others for poor academic performance). Graduate admissions committees are composed of intelligent people; do not use your application as an opportunity to insult their intelligence.

least a subset of these types of support. To facilitate these ends, we provide a condensed, student-friendly version of the results of our study in Table 1. We encourage faculty to use this as a handout they can distribute to their students who display an interest in graduate school.

\section{References}

American Psychological Association. (2001). Graduate study in psychology 2001. Washington, DC: Author.

Appleby, D. C. (2000a, November). Academic community building. Monitor on Psychology, 31, 37-41.

Appleby, D. C. (2000b, May/June). Facilitating undergraduategraduate student communication: "Family" meals. American Psychological Society Observer, pp. 27, 29.

Appleby, D. C. (2002). The teaching-advising connection. In S. F. Davis \& W. Buskist (Eds.), The teaching of psychology: Essays in honor of Wilbert J. McKeachie and Charles L. Brewer (pp. 121-139). Mahwah, NJ: Lawrence Erlbaum Associates, Inc.

Appleby, D. C. (2003a). The savvy psychology major. Dubuque, IA: Kendall/Hunt.

Appleby, D. C. (2003b, August). Transforming psychology majors into book authors at IUPUI. In B. T. Loher (Chair), Overview of orientation and career planning courses in psychology. Symposium conducted at the annual meeting of the American Psychological Association, Toronto, Ontario, Canada.

Buskist, W., \& Sherburne, T. R. (1996). Preparing for graduate study in psychology: 101 questions and answers. Boston: Allyn \& Bacon.

Crookston, B. B. (1972). A developmental view of academic advising as teaching. Journal of College Student Personnel, 13, 12-17.

Keith-Spiegel, P., \& Wiederman, M. W. (2000). The complete guide to graduate school admission: Psychology, counseling, and related professions. Mahwah, NJ: Lawrence Erlbaum Associates, Inc.

Kinder, B. N., \& Walfish, S. (2001). Perspectives on applying to graduate school. In S. Walfish \& A. K. Hess (Eds.), Succeeding in graduate school (pp. 61-73). Mahwah, NJ: Lawrence Erlbaum Associates, Inc.

Kuther, T. L. (2003). The psychology major's handbook. Belmont, CA: Wadsworth.

Kuther, T. L. (2004). Graduate study in psychology: Your guide to success. Springfield, IL: Thomas.

Landrum, R. E., \& Davis, S. F. (2003). The psychology major: Career options and strategies for success (2nd ed.). Upper Saddle River, NJ: Prentice Hall.

Landrum, R. E., Shoemaker, C. S., \& Davis, S. F. (2003). Important topics in an introduction to the psychology major course. Teaching of Psychology, 30, 48-51.

Lloyd, M. (2001). Graduate school: The application process. Retrieved November 26, 2004, from http://www.psywww.com/careers/ applicat.htm

McCracken, G. (1988). The long interview. Newbury Park, CA: Sage. 
Miles, M. B., \& Huberman, A. M. (1994). Qualitative data analysis: An expanded sourcebook (2nd ed.). Thousand Oaks, CA: Sage.

Morgan, B. L., \& Korschgen, A. J. (2005). Majoring in psych?: Options for psychology undergraduates (3rd ed.). Boston: Allyn \& Bacon.

Oles, H. J., \& Cooper, R. G., Jr. (1988). The professional seminar: A new method for student advisement. In P. J. Woods (Ed.), Is psychology the major for them? (pp. 61-63). Washington, DC: American Psychological Association.

Patton, M. Q. (1990). Qualitative evaluation and research methods (2nd ed.). Newbury Park, CA: Sage.

Peterson's. (2001). Graduate programs in psychology 2002. Lawrenceville, NJ: Author.

Sayette, M. A., Mayne, T. J., \& Norcross, J. C. (2004). Insider's guide to graduate programs in clinical $\mathbb{E}$ counseling psychology: 2004/2005 edition. New York: Guilford.

Taylor-Cooke, P., \& Appleby, D. C. (2002). The graduate school application process. Retrieved January 9, 2005, from http://www.psynt.iupui. edu/Users/dappleby/undergrad/images/process.ppt
Thomas, J. R., \& Nelson, J. K. (2001). Research methods in physical activity (4th ed.). Champaign, IL: Human Kinetics.

Ware, M. E., Busch-Rossnagel, N. A., Crider, A. B., Gray-Shellberg, L., Hale, K., Lloyd, M. A., Rivera-Medina, E., \& Sgro, J. A. (1993). Developing and improving advising: Challenges to prepare students for life. In T. V. McGovern (Ed.), Handbook for enhancing undergraduate education in psychology (pp. 47-70). Washington, DC: American Psychological Association.

\section{Notes}

1. We thank Becky May for her help during the data collection process and three anonymous reviewers for their helpful suggestions.

2. Send correspondence to Drew C. Appleby, Department of Psychology, Indiana University-Purdue University Indianapolis, 402 North Blackford Street, Indianapolis, IN 46202-3275; email: dappleby@iupui.edu. 
Copyright of Teaching of Psychology is the property of Lawrence Erlbaum Associates and its content may not be copied or emailed to multiple sites or posted to a listserv without the copyright holder's express written permission. However, users may print, download, or email articles for individual use. 